\title{
Same Bed, Different Dreams? Structural Factors and Leadership Characteristics of Central Government Agency Reform in China
}

\author{
Running Head: Central Agency Reform in China
}

\author{
Liang Ma, liangma@ruc.edu.cn \\ Associate Professor, School of Public Administration and Policy, Renmin University \\ of China, China
}

\section{Tom Christensen, tom.christensen@stv.uio.no}

Visiting Professor, School of Public Administration and Policy, Renmin University of China, China

Professor of Public Administration and Policy at the Department of Political Science, University of Oslo, Norway

Acknowledgement: An earlier version of this paper was presented at the International Public Management Network (IPMN) 2017 Conference, 17th-18th August 2017, Shanghai, China. The authors would like to thank Jiannan Wu, Xueyong Zhan, among others, for helpful comments. We are also grateful for informative comments from the guest editors and three anonymous reviewers. We thank the National Natural Science Foundation of China (NSFC) (Grant No.: 71774164; 71633004) for financial support. 


\begin{abstract}
The reorganization of government agencies can be studied as a pre-reform process in terms of the structural changes made, or as a post-reform process in terms of the effects of the reorganization. In this study of two mergers of agencies in China's central administration, we focus on structural features and the post-merger process, paying special attention to structural and cultural integration. Our qualitative analyses reveal that the National Health and Family Planning Commission (NHFPC) is considered to have been more successful in merging agencies and integrating functions than the State Administration for Press, Publications, Radio, Film and Television (SAPPRFT). We found that using physical arrangements and leadership features as explanatory variables generated helpful theoretical and policy implications for organizational architecture and public sector reforms.
\end{abstract}




\section{INTRODUCTION}

Public organizations are continuously undergoing reorganization and restructuring, such as major mergers, to achieve public goals and to strengthen their position in public decision-making processes (Pollitt and Bouckeart 2011). In recent decades, we have seen public restructuring move from New Public Management (NPM), which brought increased vertical and horizontal specialization, to post-NPM with its focus on vertical and horizontal integration (Christensen and Lægreid 2007). Our study focuses on two post-NPM mergers in China's central administration.

Studying reorganizations of public organizations may entail several phases or aspects (Egeberg 2012). The most frequent approach is to study the processes leading up to decisions on reorganizations. Another possibility is to study the formal structural changes made, which means analyzing old and new structures in order to grasp what has changed. A third is to study the post-reorganization phase, i.e. the point at which an organization has to implement and adapt to the new structure. A fourth is to look at the effects of the new structure, which may be either the narrower effects, on influence patterns, for example, or the broader social effects. The last phase is the least studied. Our study sets out to examine the second and third phases.

Our study combines two theoretical points of departure for studying mergers of public organizations. One is an instrumental-structural perspective drawn from organization theory and the great tradition of Gulick (1937) and March and Simon (1957) and used in several large studies of reorganizations over the years, particularly in Western Europe (Egeberg 2012; Lægreid and Verhoest 2010; Verhoest et al. 2010). 
Following Egeberg's (2012) organization design model, we focus on two formal aspects of reorganization, namely, the formal structure and the physical structure, meaning whether units are co-located or not. The second perspective is a cultural perspective based on Selznick's (1957) theory of the importance of institutional norms and values in public organizations. His concepts of critical decisions and 'statemanship' lead us to focus on leadership selection and leadership abilities. Our contribution to the literature on reorganizations is to analyze how structural and cultural factors and their dynamics work in a Chinese context.

The main questions posed in this study are accordingly:

- What are the similarities and differences in the newly merged structures in the two cases studied?

- Why are the post-merger processes perceived differently in the two cases? What is the relevance of the structural and cultural factors studied, i.e. the formal functional integration and physical structure, and the leadership selection and abilities and their dynamics?

The past decade has witnessed the introduction of "super-departments" in the 2008 and 2013 reforms of the Chinese central administration. This provides an ideal context to learn about post-reform processes (Dong, Christensen, and Painter 2010; Ma 2016). In a bid to reduce the number of cabinet members and ministries, the State Council (SC) merged commissions and agencies sharing pertinent functions to form mega-ministries. For instance, the National Population and Family Planning Commission (NPFPC) and the Ministry of Health $(\mathrm{MoH})$ were amalgamated into the National Health and Family 
Planning Commission (NHFPC). By the same token, the State Administration of Press, Publications, Radio, Film and Television (SAPPRFT) was created out of the State Administration of Radio, Film, and Television (SARFT) and the General Administration of Press and Publications (GAPP). Apart from anecdotes and normative analyses, we know little about the processes and mechanisms of this reorganization and post-reform processes.

In this article we draw on in-depth interviews, archives, and case studies to identify the key strategies of structural and functional integration. The analyses of archival and interview data help to reveal the processes of organizational change in the central government. The findings suggest that the various implementations and adaptations of the mergers may be explained by a dynamic interaction between structural and cultural factors; some of the latter clearly show specifically Chinese characteristics. We discuss the theoretical implications of our results and conclude with suggestions for institutional reforms and future research avenues.

\section{THEORETICAL APPROACH}

\section{Two Basic Perspectives}

An instrumental-structural perspective is rather fundamental to studies of public administration and reforms. The point of departure is not 'economic man' but ‘administrative man' (Simon 1957), meaning that actors are supposed to be rational but in reality have 'bounded rationality'. This means that their memories, attention, and capacity are limited and they have to select decision-making premises when they make 
decisions. They are helped in this selection process by the formal structure of public organizations, which modify some but not all of their rationality constraints (March and Olsen 1976). The point of departure of this perspective is that leaders are important because they take the most important decisions and that change and reform in public organizations are both possible and necessary (Christensen et al. 2007).

Political-administrative control and rational calculation are central concepts in this perspective (Dahl and Lindblom 1953). Leaders will try to control both the way reform processes are organized and which actors participate, regarding both the pre-reform and post-reform processes (Patashnik 2008). Rational calculation deals with organizational thinking, i.e. do the leaders have clear goals and resources, and a reasonable understanding of what can be expected from the reform processes?

A cultural perspective sees public organizations evolving slowly via unplanned natural processes (Scott and Davis 2006). These processes, often labeled institutionalization processes, create a unique cultural identity of informal norms and values, reflecting an adaptation to internal pressure and external pressure from the task environment (Selznick 1957). Cultural features may denote both features of politicaladministrative systems in general and of individual public organizations.

Using such a perspective to understand reforms may involve a number of different elements. First, path dependency (Krasner 1988; March 1994) means that historical trajectories heavily influence current thought and actions, which may both further and obstruct reorganizations and reforms. Here the degree of cultural compatibility is crucial (Brunsson and Olsen 1993). Second, in the cultural thinking of Selznick (1957) 
the concept of 'critical decisions', i.e. policy decisions that can change the cultural path, including decisions on reforms and change, is important. Leaders are carriers of 'historical necessities' and their critical decisions should attend to defining and operationalizing the mission and role of institutions based on constraints, score high on the 'embodiment of purpose', use symbols and rituals, and pay heed to recruitment, training and 'indoctrination' and to solving conflicts. If they manage to do this, they will score high on 'statesmanship'.

Mergers According to the Two Perspectives

There are many reasons for mergers. One might be a change of political leadership, in which case the new leadership strives to fulfill new political goals through reorganizations, which may or may not be related to larger reforms. Another reason could be a reshuffling of the political leadership, leading to structural change. A third could be that administrative units themselves initiate mergers for various reasons, while a fourth reason for a merger might be major changes in the technical, economic, social or political environment. The mergers we look at seem to be motivated by a combination of these reasons.

Using an instrumental-structural perspective, we can take Luther Gulick's (1937) basic concepts of specialization and coordination as a point of departure. Every public organization is specialized according to a vertical dimension, which tells us something about the hierarchy, leadership levels and allocation of authority, and a horizontal dimension, which indicates the degree of specialization according to the principles of purpose, process, clientele or geography on the same level (Gulick 1937). 
Strongly specialized public organizations often become rather fragmented - a typical effect of New Public Management (NPM) (Pollitt and Bouckeart 2011). This in turn often leads to efforts to bring about more coordination, a typical feature of post-NPM (Christensen and Lægreid 2007). Coordination has two main dimensions, one verticalhorizontal and the other external-internal (see Table 1) (Christensen and Lægreid 2008). The most relevant combination in our case is internal, horizontal coordination, meaning the merging of government units on the same level. In a seminal study of merging federal agencies, Karen Hult (1987) shows that there are substantial effects on contact patterns both internally and externally. According to Egeberg, Gornitzka, and Trondal (2016), the effects of mergers will be enhanced if they change the principles of horizontal specialization or produce a mixture of former units. So the task is to try to design the new merged organization without paying much heed to the structure of the former organizations.

$<<<$ Insert Table 1 about here $>>>$

The first structural variable we will use is the functional integration one. While both the cases we look at here are about merging two public organizations, there are at least three ways of doing this (Egeberg 2012). First, scoring low on this variable means that units from the old organizations continue to exist within the framework of the new organization. Second, a medium score would indicate that some units are merged while others remain as they were. Third, scoring high on functional integration means that all the former units are merged or melded in the new structure. The latter scenario is often 
the one espoused in mergers of public organizations because it is believed to have the greatest effect on actions and efficiency, but at the same time, this often poses challenges.

Coordination and mergers may be influenced by physical structure, meaning in our case whether the former organizations are co-located in the new one or not. Physical structure can be both symbolic and instrumental, whereby the latter is most relevant for us (Goodsell 1977). Communication, interaction patterns and actions are influenced by the design of the physical structure. A merger between two public organizations that implies physical separation, for example in two locations or buildings, has less chance of succeeding than locating the former organizations in one building (Egeberg 2012). Separation means that the likelihood of old interaction patterns continuing is high, depending on functional integration. Hence, formal and physical redesign are in a dynamic relationship.

According to a cultural perspective, coordination through mergers is informal rather than formal. A central mechanism is what organizational units and civil servants should do according to the logic of appropriateness, furthered through socialization (March and Olsen 1989). Central factors here are a common identity and a high level of mutual trust between ministries and agencies, which makes it easier to coordinate many activities, because units and civil servants know what they are supposed to do and how to act, something which in turn further enhances mutual trust. Krasner indicates an ideal with high scores on two factors: one is vertical depth, which denotes the degree to which an actor is committed to the common norms and values of a public 
organization, i.e. how easy it is to act in an appropriate way. The other is horizontal width, which focuses on the degree to which different units and actors in an organizational unit have the same type of identity, norms and values, i.e. how integrated the institutions are horizontally.

More specifically, we follow Selznick's (1957) focus on the role of leaders in the integration process alluded to above. We use two central variables connected to his concept of 'critical decisions', namely leadership recruitment and leadership ability. Leadership recruitment means characteristics of the new leaders in the merged public organizations. How were they recruited, and what background and experience do they have? Leadership ability denotes the extent to which the new leaders manage to create a feeling of belonging and commitment to the new organization, i.e. their ability to bring about cultural integration by breaking with the cultural past (Kingdon 1984).

If we combine the insights from the structural and cultural perspectives, the ideal conditions for successful mergers would be functional integration and co-location, the balanced and impartial recruitment of the new leaders (i.e., they see the former units as equal partners) and competent leadership, including the ability to bring about cultural integration.

Hypotheses about the Post-merger Process

Based on the reasoning above we formulated the following hypotheses:

- H1: Functional integration of units in a merged organization is an important precondition for a successful post-reform process. 
- H2: Co-location of the former organizations furthers a successful post-reform process.

- H3: The balanced recruitment of a new leader who is impartial and competent furthers a successful post-reform process.

- H4: A new leader with the ability to bring about cultural integration in the new organization is a precondition for a successful post-reform process.

- H5: The reinforcement of the structural and cultural variables is a major precondition for a successful post-reform process.

\section{CONTEXT AND METHODS}

\section{Context}

China is governed by a sole ruling party, the Communist Party of China (CPC), and its government apparatus is organized hierarchically. At the central level the National People's Congress (NPC) as the legislature is a symbolic body representing the constituency. The CPC Central Committee holds de facto political power, and the State Council (SC) as the cabinet is its executive authority. The SC is composed of various ministries, commissions/agencies, administrations, state bureaus, offices, and institutions. Local government is structured in four tiers, consisting of provinces, prefectures, counties, and townships. China has a unitary regime, and government machinery at each level is organized substantially in the same way. Party and state organs are conventionally juxtaposed, but party organs (e.g., Department of Propaganda) usually have superior decision-making power because their heads are often members 
of the Standing Committee of the CPC.

Given the size of China, escalating regional disparities, and rapid socioeconomic transition, it is not surprising that the government is composed of dozens if not indeed hundreds of functional subunits. If we take all the organs directly under the SC into account, there are about eighty independent agencies (Ma and Christensen 2017). The SC has been trying to cut the number of agencies and streamline overlapping functions since China was founded in 1949, and rounds of institutional reforms have been implemented by almost every administration (five years) (Ma 2017). As mentioned above, the 2008 and 2013 rounds of institutional reform primarily merged some ministries and central agencies into "super-ministries". The main rationale behind merging ministries is to reduce their number and to streamline cross-agency coordination (Dong, Christensen, and Painter 2010). Coordination among strong, albeit fragmented ministries is usually challenging owing to their different and even conflicting interests. By merging ministries, previous coordination problems are internalized, which helps to make coordination more effective (Ma 2016). Another equally important purpose of mergers is to adjust the functions of central agencies, e.g., to transform their mission from central planning to market regulation and from commanding to service delivery (Lan 2001). In line with the rapid and extensive national socioeconomic transition, government agencies have to reinvent themselves to fit new circumstances (Xue and Zhong 2012).

\section{Case Selection}

Given the subtle and hidden nature of agency mergers, it is appropriate to use 
qualitative methods in case study research design. As a small-N qualitative inquiry approach, a case study is appropriate for in-depth narrative and a 'thick description' of phenomena of interest. There are three case study approaches, namely co-variational analysis, causal-process tracing, and congruence analysis, and they are different in their causal inference (Blatter and Haverland 2012). In this study, our aim is to explore the structural, functional, and leadership antecedents of post-merger success. We thus adopted the co-variational analysis approach in the case study. Such an approach is variable-centric, and the variation of key independent variables is used to explain the variation of dependent variables (Gerring 2007).

We chose NHFPC and SAPPRFT as our cases for two reasons: comparability and accessibility. The two cases are typical institutional mergers, as two strong organs were horizontally amalgamated. While other cases are relevant and will also be referred to, they are not as comparable as the cases of the NHFPC and the SAPPRFT. Organizational change can take various forms, including secession, splitting, absorption, merger, and other complex reorganizations (Rolland and Roness 2011), and it makes sense to compare equivalent change processes, i.e., mergers. As elaborated below, the two cases are rather different with regard to the independent variables (e.g., structural configuration and leadership) but quite similar with respect to other variables (e.g., motives and preconditions for the mergers). By controlling for similar variables we are able to infer causal relationships between the independent variables and the dependent variable (i.e., success or effectiveness of post-merger integration), which helps to identify the key variables at work during and after the merging process. 
Second, the authors gained access to key informants involved in the merging process of the two agencies, which helped to identify key facts during and after institutional amalgamation. The study of central agencies in China is disproportionally weaker than research into local government, which can be partially attributed to the lack of available data (Ma 2017). Particularly when studying agency mergers, which are largely invisible from the outside, it is imperative to consult insiders about the nuances of the process. Given the political sensitivity and subtleness of mergers, officials are often reluctant to publically discuss post-merger difficulties and struggles, so only insiders can be trusted.

\section{Data Collection and Analysis}

In this article we draw on in-depth interviews and archives to examine the structural and functional integration of the two agencies. Researchers often encounter serious challenges in conducting elite interviews designed to delve into subtle and hidden politics in authoritarian China (Read 2010). For politically sensitive topics like postmerger integration, it is not unusual for there to be few media reports or public debates. The "insiders" would not talk honestly about real situations with people without strong personal ties (guanxi) (Ang 2017), and we relied on our acquaintances (e.g., alumni) to approach interviewees by the snowball method. We interviewed a total of seven employees of the General Office of the NHFPC (4) and SAPPRFT (3), which is the command center for all functional offices.

We used semi-structured interviews but made notes rather than recording the responses, otherwise the interviewees might not have answered our questions frankly. Once we had completed the interviews, we immediately transcribed the field notes for 
further analysis. We met the interviewees at cafes or restaurants in their vicinity, and the interviews on average ran for one to two hours. We interviewed the civil servants separately in private, which is more suitable than group discussions in eliciting honest responses. If additional data were needed, we interviewed them by telephone for verifications. In the process of interviewing, we asked the interviewees about the processes of merging in retrospect, and they gave vivid examples to help us to understand the challenges of post-merger integration. We also asked the participants about their perceptions of success and failure, the pros and cons of mergers, as well as the obstacles to and conditions of post-merger integration. All the interviewees had gone through the entire pre- and post-restructuring process, which helped us to crosscheck their opinions towards mergers.

We also gleaned second-hand data from government gazettes, official documents, and online and media reports, which provided rich descriptive material for understanding the merger process. The analyses of archival and interview data helped to reveal the processes of organizational change in the central government. In the covariational analysis, multiple observations were used to generate the indicators or scores of the variables, and their co-variations were then elaborated to draw causal inferences. To measure the variables under investigation, we used both interview and archival data from multiple sources, which triangulated to reveal reliable and valid observations of the independent and dependent variables. Archival data helped us to determine the key attributes of reorganization, while interview data facilitated tapping into the hidden rationales and processes of organizational change. 
The data were manually coded and analyzed to elicit co-variational patterns (e.g., whether the independent and dependent variables changed in line with our theoretical predictions) until theoretical saturation, meaning that additional interviews would not contribute new insights about theoretical propositions. For instance, we used two interviewees' materials to gauge the extent to which new leaders were competent in bringing about cultural integration in the agencies, and data from an additional one or two interviewees were employed to check the explanations. Such a qualitative patternmatching approach is suitable for the co-variational analyses reported in this paper, which is an exploratory study of post-merger integration.

\section{MAIN FEATURES OF THE MERGERS AND THE POST- MERGER PROCESS}

The Case of the National Health and Family Planning Commission (NHFPC)

The Ministry of Health $(\mathrm{MoH})$ and the National Population and Family Planning Commission (NPFPC) have a shared history, but the missions and values of the two agencies have always been rather different, which gave rise to incongruent interests and conflicting policies. Founded in 1954, the MoH's primary task was to further public health by regulating pharmacies, hospitals, and clinics. The MoH was also responsible for things like immunization and disease control. Given its mission to deliver various healthcare services to citizens, the $\mathrm{MoH}$ is largely service-oriented and liberal. The Family Planning Division was set up in 1962 as an agency subordinate to the MoH. In 1964, it was upgraded to become the National Family Planning Commission (NFPC), 
an independent agency in charge of family planning. The NFPC was abolished in 1968 and the MoH took over its functions, but it was relaunched in 1981 as a formal agency under the SC, primarily because national leaders had been increasingly concerned about the soaring population. It was renamed the NPFPC in 2003, and then in 2013 was merged with the MoH to form the NHFPC. Given the declining salience of population control policies implemented by the NFPC, the SC aimed to merge the two agencies for reasons of bureaucratic simplification and downsizing.

The NPFPC's main task was to implement population control and family planning policy, which was notorious for its stringent measures such as compulsory abortion and penalties for having more than one child. As China was the most populous country in the world, the Chinese government was very concerned about rapid population growth, and tough measures were used to control the population. Since the early 1980s, with the exception of minorities and families whose first child was handicapped, each family has been allowed to have only one child. Later, the steadily declining fertility rate and the rapid aging of the population led China to gradually adopt more benign policies. The two agencies that later merged had overlapping functions in maternal and child health as well as community health, but their coordination efforts often failed owing to differing standpoints and ideas (see Table 2). The two agencies differed in their missions and underlying values, and their amalgamation was expected to result in intense bargaining and conflicts.

In terms of history, mission valence, and agency size, the MoH outperformed the NPFPC. In terms of the number of employees, the MoH (387) was about 2.5 times 
larger than the NPFPC (143). During its early years, the NPFPC could thus be considered a subsidiary of the MoH (see Table 3). But the NHFPC reflects the interests of the NPFPC more than those of the MoH. Among the departments subordinate to the NHFPC, two thirds are headed by people from the NPFPC. Even the name of the new agency is controversial, being either a "ministry" or a "commission", and it raises the issue of whether "health" or "family planning" should be named first. This rhetorically reflects the power bargaining between the two agencies. The name of the new agency is primarily a successor to the NPFPC and partially reflects the strong power of its former leaders, in other words, the NPFPC absorbed the MoH rather than vice versa. However, as the interviewee emphasized, such an arrangement also suggests that the merger of the two agencies constituted a balancing act. By treating the two agencies as equal and even slightly favoring the NPFPC, the new NHFPC achieves a power balance which is pivotal to a sustainable and harmonious integration. Otherwise, the weaker side would feel unfairly treated and might even make trouble.

$<<<$ Insert Table 2 and Table 3 about here $>>$

Li Bin was deputy director of the NPFPC from July 2007 and was appointed director in March 2008. She was transferred to govern Anhui province in December 2011 and then became the director of the NHFPC in March 2013. Chen Zhu had been minister of health since June 2007, but he was later appointed vice chairman of the Standing Committee of the NPC (vice-national level) and did not succeed in the NHFPC. Five vice-ministers share the administration of NHFPC. According to one interviewee 
(Interview-A-20170712), Li Bin has shown excellent leadership in reconciling the two agencies.

"Director Li is a female leader, and she is good at bringing us together. In our commission, no one has failed to be convinced by her charisma. Although she does not have a career background in medicine, she is a veteran in respecting and working with health professionals. She knows how to make the merger process run smoothly and steadily and would not let anyone fall behind. It is not only about work capability, but primarily about having the emotional intelligence to achieve coordination and balance. The Central Committee of the Party selected the right leader, and she implemented the merger process very successfully, even exceeding expectations."

Female leaders are often more competent than male leaders at handling interpersonal relations and conflict resolution (Eagly and Carli 2003), which helps to streamline the merger process. Particularly in China, where female senior leaders are disproportionally under-represented, their proactive steering helps to soften tensions, resolve conflicts, and harmonize new organizations.

The NPFPC oversaw nine agencies while the $\mathrm{MoH}$ coordinated fifteen subordinate bodies; the resulting NHFPC is composed of twenty-one agencies. Three new agencies (Department of Community Family Planning, Department of Family Development, and Department of Healthcare Reform) were formed, while others were virtually inherited from the ministry and NPFPC. Six equivalent subunits in charge of similar functions were integrated, while nine former $\mathrm{MoH}$ agencies and three former NPFPC agencies continued as before. Healthcare is a professional and scientific policy area, while family planning is more about administration and policy implementation, suggesting two rather different organizational cultures. We find that the subunits were structurally combined, albeit functionally fragmented, with only administrative amalgamation without core cross-functional integration. Only the administrative organs (e.g., general office, human resources, finance, and information) were combined, while functional 
subunits (core task organs) were kept virtually unchanged, which reflects functionally different tasks. In other words, the agencies were partly functionally pooled instead of being wholly integrated. Despite the fact that the merger had entailed partial structural combination instead of functional integration, one interviewee thought that the reorganization had been rather successful (Interview-B-20170712).

"The amalgamation of the NPFPC and the MoH into the NHFPC is a successful and profound integration. The new commission was ready after only about half a year, and currently it is really a wholly integrated institution. While the cross-fertilization of functions between former independent agencies has not been well completed, the people have been fully merged. You are among us and we are among you. No one considers where I come from, and all of us belong to the same 'family.' Nevertheless, we should not overrate the merger, at least no-one has counteracted or undermined the enterprise."

Although the two former office blocks were kept, both agencies and personnel were mixed and co-located, which helped to replace the old departmental identity and consolidate a new organizational identity. Summing up our major variables: concerning the structural variables, this merger shows that the formerly separate organizations were not functionally integrated, but co-located. Concerning the two leadership variables, the new director scored high on both. She was recruited in a balanced process, was seen as impartial and certainly competent, and scored very high on bringing about cultural integration.

The Case of the State Administration of Press, Publications, Radio, Film and Television (SAPPRFT)

General Administration for Press and Publications (GAPP) and the State Administration for Radio, Film and Television (SARFT) were combined into SAPPRFT in 2013, but the merger process was not well managed. GAPP (and the State 
Copyright Administration) was in charge of print media (press and publications) regulation and copyright protection, while SARFT primarily regulated various digital media including radio, film, television, and online media. It also directly controlled China Central Television (CCTV), China National Radio, and many film and TV studios. Given their overlapping functions and the increasing media convergence, it seemed reasonable for the SC to merge the two agencies. Despite the creation of SAPPRFT, the merger was largely superficial and did not show any sign of deep integration.

The two agencies were both established in 1949 as branches of the Department of Propaganda of the CPC Central Committee (CDP), and SARFT and GAPP became autonomous in 1998 and 2001 respectively. Together with the Ministry of Culture, they are all coordinated by the CDP, and political oversight and ideological intervention complicated cross-agency coordination. Each of the two former agencies covered extensive aspects of media and press, and their merger generated a complex blending of isolated entities, which gave rise to a long and painful process of integration. Media corporations and journalists wanting to span the print and digital media had to be approved by both agencies before being merged, since they covered different stages of content production and communications. Such fragmented regulations stifled media convergence and calls for institutional and industrial amalgamation.

When the reform proposal was submitted by the SC to the NPC in March 2013, SAPPRFT was mocked by the public for having the longest name of all the central agencies. The NPC deputies reviewing the proposal were also concerned about the 
insurmountable challenges of merging the two agencies owing to entrenched institutional interests and intertwining functions. Instead of simply using "communications" or "media", all prior media types (e.g., radio, press, TV) are listed in the name of the new agency, implying that each of them was reluctant to lose its status. Following the suggestions of the NPC deputies, the SC shortened its name from fourteen to ten Chinese characters. Still, all media types were preserved although some were abbreviated, and it is still among the institutions with the longest names. It was acknowledged that this outcome was a compromise and that people were worried about the risk of integration, suggesting difficulties in overcoming the boundaries between its subunits. ${ }^{1}$

Both GAPP and SARFT oversaw twelve subunits, and the resulting SAPPRFT is composed of twenty-two agencies (see Table 4). Three new agencies (Department of Finance, Department of Public Service, and Department of Import Administration) were formed, while others were almost inherited or renamed. Five agencies with overlapping functions were integrated (e.g., General Office, Department of Personnel), and both GAPP and SARFT had seven former agencies that were kept unchanged. SARFT (292) employed more than GAPP (196), and the workforce of SAPPRFT (508) is roughly the sum of the two former agencies (see Table 5). The heads of the subunits in most cases remained in their posts and job rotation was rare, suggesting the merger was superficial. Although the two agencies have been merged, they continue to behave

\footnotetext{
1 Wang, Qingying. The combination is not only about the name but also about the duties---An observation of the establishment of SAPPRFT. China Journalists, 2013-06-17, http://media. people. com.cn/n/2013/0617/c365259-21866984.html.
} 
almost independently. The official web portals of the two agencies were not merged, and the SAPPRFT website was able to go online only after the first national census of the government website at the end of 2015, almost three years after its restructuring. GAPP (www.gapp.gov.cn) stopped updating on November 9, 2016, and SARFT went online (www.sarft.gov.cn) on May 27, 2017. The new website is based on the SARFT website, while the GAPP website has been totally discarded. We were told by an interviewee that such integration was requested by superior authorities, yet there were still two separate teams running the website (Interview-F-20171219).

\section{$<<<$ Insert Table 4 and Table 5 about here $>>$}

The two agencies are split in their core missions owing to their different ideological directions. SARFT was conservative and more concerned with ideological propaganda and media censorship, while GAPP was more liberal and primarily steered the copyright and media industries. The two agencies are physically separated in different buildings and locations, and cross-agency coordination is largely limited. The two working locations are both in Xicheng District, but they are about four kilometers away and owing to traffic congestion it takes about fifteen minutes to drive from one to the other. The agencies are still geographically clustered alongside SARFT (Fuxingmenwai Street) and GAPP (Xuanwumenwai Street) as are their residential apartments. They look like two independent kingdoms or clubs under the same umbrella, without a shared mindset or identity. This split identity was also vividly disclosed by an interviewee, 
who publicly accused both of them of profiting at the other's expense following the merger process (Interview-D-20170321).

"To be honest, our integration is at best superficial, and the new agency is divided against itself and full of internal dissent. We are not a coherent family. We are still two separate coalitions. Since we are still working at different locations without concrete crossovers in job arrangement, we don't have very intensive interactions. They blame us for their loss of power and interests, and we accuse them of encroaching on our traditional territory. This is not a secret, and our conflicts are public."

The leadership succession further aggravated cross-agency tensions, since the head of one former agency (SARFT) became the new head of the super-department (SAPPRFT), which frustrated the head of the other former agency (GAPP). Cai Fuchao became the director of SAPPRFT in March 2013. He had had a long history of working for the Beijing Daily and the Beijing Propaganda Department before becoming the director of SARFT in February 2011. Liu Binjie, the former GAPP director since 2007, was transferred to the NPC (almost a retirement position). Jiang Jianguo, deputy director of GAPP since 2008, was appointed deputy director and party secretary of SAPPRFT. In November 2016, Cai was transferred to the Chinese People's Political Consultative Conference (CPPCC), and Nie Chenxi (former deputy director of SARFT since 2012) was promoted from deputy director to director. These leadership successions suggest that officials from SARFT outperformed those in GAPP in the competition to steer SAPPRFT, which gave rise to a major power struggle that undermined structural and functional integration. As one interviewee acknowledged (Interview-E-20170405),

"The two agencies competed fiercely with each other in some domains before merging, primarily because of vested interests in the cultural and media industry. The toughest problem of the merger process is the pecking order of the former leaders of the two agencies. The new director cannot keep a balance between the two factions, and he overwhelmingly leans towards his prior 
subunits and colleagues. We felt that they have gone too far and even touched our emotional bottom line. The teething process has been gradual, painful, and too long, and we have all become exhausted fighting against each other."

Summing up, according to our structural variables, this merger shows a lack of functional integration that is even more obvious than in the first case. A big difference is also that the two merged units were allowed to continue in their separate locations.

Second, the cultural variable shows an unbalanced and conflict-ridden leadership recruitment process; the leader was not seen as impartial, and certainly did not score high on his ability to bring about cultural integration.

\section{DISCUSSION, CONCLUSIONS AND IMPLICATIONS}

Our results show that the NHFPC merger process was rather harmonious and effortless, while the SAPPRFT merger was more characterized by tensions and conflicts. According to Patashnik (2008), the decision-making and the implementation processes are normally closely connected, so that continued commitment from leaders is very important. Thus, successful implementation is connected to a smooth decision-making and post-reform process.

Our first research question concerned what characterized the structural changes made in the two cases. Looking at the formal structural changes made, they are rather similar in the sense that it was mainly administrative units that were merged, while most of the functional-professional units were kept unchanged within the new formal boundaries. This is partly understandable because they are rather different, but partly also typical for such reorganization processes, because it is much more difficult to achieve functional integration in mergers (Hult 1987). In view of this, the NHFPC case 
implies slightly more functional integration (see Table 6).

$<<<$ Insert Table 6 about here $>>>$

This brings us to our first hypothesis: seen from an instrumental-structural perspective, given the limited extent of functional integration, differences in functional integration cannot explain why NHFPC is seen as a success while SAPPRFT is more of a failure. So $\mathrm{H} 1$ is not confirmed.

Our second hypothesis was about co-location. Explaining the diverse features of the post-reform process, co-location of the formerly separate organizations in the NHFPC would seem to be important, while this was not the case for SAPPRFT. Egeberg (2012) shows that formal coordination and mergers are easier to achieve if public organizations are co-located. The main reason for this is that the new formal boundary then has more of an effect on interaction and decisions. Added to this, the rather limited functional integration in the new merged organizations in our two cases makes it even easier to continue with former interaction patterns.

Seen from a cultural point of view, physical separation in a merged organization makes it easier for the component organizations to continue their traditional cultural path and thus presents an obstacle to cultural integration (Christensen et al. 2007). According to Krasner's (1988) concept, there will be a low score on horizontal width, meaning cultural integration between units on the same level. There is also a symbolic side to this, following the reasoning by Charles Goodsell (1977), i.e. physical separation 
signals that continuing as a separate unit within a whole is feasible and appropriate. So Hypothesis 2 seems to be confirmed.

Moving on to hypotheses $\mathrm{H} 3$ and $\mathrm{H} 4$, based on the cultural perspective, the two cases were rather different regarding the two leadership variables - recruitment and ability - and therefore scored differently. Concerning the NHFPC case, the leadership recruitment was seen as balanced and impartial and resulted in the appointment of a very competent and experienced leader, while this was not the case for SAPPRFT, where the recruitment was controversial and the new director was seen as representing one of the former organizations, which led to resentment from the 'loser'. So H3 seems to have been confirmed.

Furthermore, the new director of NHFPC scored much higher on making the merged organization function well. She fulfilled Selznick's (1957) notions of being competent to take 'critical decisions' and show 'statemanship', having obviously handled the post-reform process and the launch of the new organization well in terms of cultural integration, motivating and leading people through her charisma. There may be a gender factor involved here. She also scored high on clear means-end thinking (Aberbach and Christensen 2014). By comparison, the failure to implement SAPPRFT well seems to have resulted from a lack of instrumental ability on the part of the new director and a much lower degree of legitimacy because he is seen as representing the strongest of the former organizations in the merger, and is less able to lead the way culturally within the organization. So H4 seems to be confirmed.

The last hypothesis concerns whether we see a reinforcement of structural and 
cultural variables in the two cases. This seems to be true, but it does not include functional integration. In the NHFPC case, co-location, a successful recruitment process, and strong leadership abilities combine to explain a rather successful postreform process. In the SAPPRFT case the opposite was true, meaning physical separation and low legitimacy concerning leadership recruitment and leadership ability. Even though functional integration was part of the equation, we can say that H5 is mostly confirmed.

\section{The Implications for Post-Merger Integration}

So what are the main lessons learned from these cases? First, does the overall focus in China on structural amalgamation, as seen for example in two rounds of creating socalled super-departments, suggest that the Chinese government imitates and learns from the West in reforming its bureaucratic machinery (Dong, Christensen, and Painter 2010; Ma 2016)? There are very typical post-NPM features in both the merger processes. Some of the differences in how the mergers were implemented and the challenges they faced are familiar from similar Western cases (Christensen and Lægreid 2008).

But to what extent are these cases typically Chinese? We would say quite a lot. One feature is the lack of functional integration following the mergers, reflecting a longstanding resistance of public employees in China to administrative changes. Lan (2001) strongly stresses this feature in his analysis of the experience of reforms in China, which are characterized by path dependency, and of the combined challenges of streamlining and growth. Another typical feature is the rather complicated turn-over of public leaders in China controlled by the party, which tries to balance a lot of political 
and personal career considerations. In our two cases this seemed to be an advantage for the NHFPC but not for SAPPRFT, but we do not have data on how the political processes behind this played out. A formal comparison between the China cases and other contexts goes beyond the scope of this article, and we call for future studies to tap into this promising direction.

Politicians and public managers can learn a lot from the two contrasting cases about how to make the merger process and post-merger integration smoother and more successful. The implications of our findings are threefold. First, leadership matters. Without strong leadership to modify boundaries, blend subunits, and generate consensus, it is difficult to achieve a successful agency merger. The key is to maintain a balance and make everyone feel they are being fairly treated.

Second, structural amalgamation will not automatically generate functional integration, which usually requires a follow-up reform. Functional integration may be organized in a gradual and incremental manner. Once the merger has been completed, the intra-organizational reconfiguration can be implemented more easily than before when these functions belonged to different organizations.

Last, but not least, physical interactions still work in the era of internet, so co-locating subunits and employees is a key element of a merger. Although it may not be viable to house all the staff in the same building, they may still be co-located. Such personnel arrangements can help to mitigate fractional politics and rebuild organizational identity, which is crucial to the success of agency mergers.

This study is limited in two ways and we hope future research will enrich the 
literature by addressing these limitations. First, our study covers only two cases. If future studies are able to cover more cases and use quantitative methods (e.g., surveys) to elaborate on people's perceptions of structural and functional integration, this should yield more information. Our two cases are typical and our interviewees were well informed about the merger processes, but more can be achieved if other cases are included. Second, China is novel in its political and administrative regimes, and we call for future studies to examine structural and functional integration in other settings, which would help to understand public sector reforms in a comparative context. The key factors identified in this study (leadership, personnel, and physical arrangements) are not unique to the Chinese context, and they can be replicated and extended to other countries different from China in important respects (e.g., democracy, government apparatus). Despite these limitations, this study has helped to delve into the process underpinning agency mergers and to deepen our understanding of organizational restructuring.

\section{REFERENCES}

Aberbach, J. D., and T. Christensen. 2014. "Why Reforms So Often Disappoint." The American Review of Public Administration 44 (1):3-16.

Ang, Y. Y. 2017. How China Escaped the Poverty Trap. Ithaca, NY: Cornell University Press.

Blatter, J., and M. Haverland. 2012. Designing Case Studies: Explanatory Approaches in Small-N Research. New York: Palgrave Macmillan.

Brunsson, N., and J. P. Olsen. 1993. The Reforming Organization. London: Routledge.

Christensen, T., and P. Lægreid. 2007. "The Whole-of-Government Approach to Public Sector Reform." Public Administration Review 67 (6):1059-1066.

_—_. 2008. "The Challenge of Coordination in Central Government Organizations: The Norwegian Case." Public Organization Review 8 (2):97.

Christensen, T., P. Lægreid, P. G. Roness, and K. A. Røvik. 2007. Organization Theory and the Public Sector: Instrument, Culture and Myth. Aldershot, UK: Ashgate. 
Dahl, R. A., and C. E. Lindblom. 1953. Politics, Economics, and Welfare. New York: Harper \& Row.

Dong, L., T. Christensen, and M. Painter. 2010. "A Case Study of China's Administrative Reform: The Importation of the Super-Department." The American Review of Public Administration 40 (2):170-188.

Eagly, A. H., and L. L. Carli. 2003. "The Female Leadership Advantage: An Evaluation of the Evidence." The Leadership Quarterly 14 (6):807-834.

Egeberg, M. 2012. "How Bureaucratic Structure Matters: An Organizational Perspective." In The Sage Handbook of Public Administration, edited by B. G. Peters and J. Pierre. London: Sage Publications.

Egeberg, M., Å. Gornitzka, and J. Trondal. 2016. "Organization Theory." In Handbook on Theories of Governance, edited by C. Ansell and J. Torfing. Cheltenham, UK: Edward Elgar.

Gerring, J. 2007. Case Study Research: Principles and Practices. New York: Cambridge University Press.

Goodsell, C. T. 1977. "Bureaucratic Manipulation of Physical Symbols: An Empirical Study." American Journal of Political Science 21 (1):79-91.

Gulick, L. H. 1937. "Notes on the Theory of Organization." In Papers on the Science of Administration, edited by L. H. Gulick and L. F. Urwick. New York: Institute of Public Administration.

Hult, K. M. 1987. Agency Merger and Bureaucratic Redesign. Pittsburgh: University of Pittsburgh Press.

Kingdon, J. W. 1984. Agendas, Alternatives, and Public Policies. Boston: Little, Brown.

Krasner, S. D. 1988. "Sovereignty: An Institutional Perspective." Comparative Political Studies 21 (1):66-94.

Lægreid, P., and K. Verhoest. 2010. "Introduction: Reforming Public Sector Organizations." In Governance of Public Sector Organizations: Proliferation, Autonomy and Performance, edited by P. Lægreid and K. Verhoest. London: Palgrave Macmillan UK.

Lan, Z. 2001. "Understanding China's Administrative Reform." Public Administration Quarterly 24 (4):437-468.

Ma, L. 2016. "Does Super-Department Reform Improve Public Service Performance in China?" Public Management Review 18 (3):369-391.

—_ _ 2017. "Central Government Agencies in China: Toward a Research Agenda." Economic and Political Studies 5 (2):195-214.

Ma, L., and T. Christensen. 2017. "Mapping the Evolution of the Central Government Apparatus in China." International Review of Administrative Sciences forthcoming.

March, J. G. 1994. Primer on Decision Making: How Decisions Happen. New York: The Free Press.

March, J. G., and J. P. Olsen. 1976. Ambiguity and Choice in Organizations. Bergen, Norway: Universitetsforlaget. 1989. Rediscovering Institutions: The Organizational Basis of Politics. New York: The Free Press. 
Patashnik, E. M. 2008. Reforms at Risk: What Happens after Major Policy Changes Are Enacted. Princeton, NJ: Princeton University Press.

Pollitt, C., and G. Bouckeart. 2011. Public Management Reform: A Comparative Analysis - New Public Management, Governance, and the Neo-Weberian State. 3rd ed. Oxford: Oxford University Press.

Read, B. L. 2010. "More Than an Interview, Less Than Sedaka: Studying Subtle and Hidden Politics with Site-Intensive Methods." In Contemporary Chinese Politics: New Sources, Methods, and Field Strategies, edited by A. Carlson, M. E. Gallagher, K. Lieberthal and M. Manion. Cambridge: Cambridge University Press.

Rolland, V. W., and P. G. Roness. 2011. "Mapping Organizational Change in the State: Challenges and Classifications." International Journal of Public Administration 34 (6):399-409.

Scott, W. R., and G. F. Davis. 2006. Organizations and Organizing: Rational, Natural and Open Systems Perspectives. New York: Routledge.

Selznick, P. 1957. Leadership in Administration. New York: Harper \& Row.

Simon, H. A. 1957. Administrative Behavior. New York: The Free Press.

Verhoest, K., P. Roness, B. Verschuere, K. Rubecksen, and M. MacCarthaigh. 2010. Autonomy and Control of State Agencies: Comparing States and Agencies. London: Palgrave Macmillan.

Xue, L., and K. Zhong. 2012. "Domestic Reform and Global Integration: Public Administration Reform in China over the Last 30 Years." International Review of Administrative Sciences 78 (2):284-304. 


\section{Author Bios:}

Liang Ma (liangma@ruc.edu.cn) is Associate Professor at the School of Public Administration and Policy, Renmin University of China, China. He received his $\mathrm{PhD}$ in management at the School of Management, Xi'an Jiaotong University. His current research examines performance feedback, goal setting, and strategic change in public organizations.

Tom Christensen (tom.christensen@stv.uio.no) is Professor of Public Administration and Policy at the Department of Political Science, University of Oslo, Norway. He is also senior researcher at the Stein Rokkan Centre, University of Bergen, and Visiting Professor at the School of Public Administration and Policy, Renmin University of China. His current research interests deal with comparative public sector reforms, in particular questions related to accountability and reputation management. 